\title{
Work in Progress: Immersive First-Year Experience for Bioengineering Cur- ricula
}

\section{Dr. Jennifer R. Amos, University of Illinois, Urbana-Champaign}

Dr Amos joined the Bioengineering Department at the University of Illinois in 2009 and is currently a Sr Lecturer and Director of Undergraduate programs. She received her B.S. in Chemical Engineering at Texas Tech and Ph.D. in Chemical Engineering from University of South Carolina. She has developed and offered more than 5 courses since joining the faculty and has taken the lead roll in curriculum development for the department.

\section{Dr. Marcia Pool, University of Illinois, Urbana-Champaign}

Dr. Marcia Pool is a Lecturer in bioengineering at the University of Illinois at Urbana-Champaign. In her career, Marcia has been active in improving undergraduate education through developing problem-based laboratories to enhance experimental design skills; developing a preliminary design course focused on problem identification and market space (based on an industry partner's protocol); and mentoring and guiding student teams through the senior design capstone course and a translational course following senior design. To promote biomedical/bioengineering, Marcia works with Women in Engineering to offer outreach activities and is engaged at the national level as Executive Director of the biomedical engineering honor society, Alpha Eta Mu Beta.

\section{Dr. Karin Jensen, University of Illinois, Urbana-Champaign \\ Dr. John Vozenilek}




\title{
Works in Progress: Immersive first year experience for bioengineering curricula
}

\begin{abstract}
Many students choose a college major based on difficulty, selectivity, popularity, or their interpretation of the major and interest in the subject matter. Most students do not begin seeking experiences related to their profession until later in their college career. However, developing an understanding of the professional opportunities while also participating in activities related to the major allows students to solidify their choice of major, begin developing their professional identity, and begin defining their professional goals. To assist students in developing their professional identity and behavior, an immersive, first-year experience with shadowing components was developed to renovate the Introduction to Bioengineering course at the University of Illinois at Urbana-Champaign. This type of experience is designed to expose students to the professional environment with a didactic and self-reflective curriculum, thereby supporting students in their early professional development. The class was taken from a passive seminar series that broadly covered the bioengineering field to one split into three careercentered foci, each with an overview and experience: i) Industry with topics in career fair strategies, networking, information literacy, and corporate skills with a simulated industry internship to create artificial membrane for kidney dialysis, ii) Healthcare professions with topics in healthcare operations, emergency medicine, inpatient care, and electronic medical records with a clinical shadowing experience, and iii) Research with topics in experimental design, ethics, scientific literature, and translating technologies with a research laboratory shadowing experience. Students self-selected into the three sections during an advising session and were asked to provide information before classes started to help facilitate setting up the shadowing experiences. Each section had the same number of lecture and immersion hours outside of class. Assignments, which consisted of weekly reflective journals, participation, and a group poster reviewing the experience, were also kept similar between the sections. Surveys were administered at the end of the experience in order to capture students' perceived professional formation, career identity, commitment to major, and overall satisfaction with the course.
\end{abstract}

\section{Motivation}

Understanding bioengineering as the converging synthesis of medicine, life sciences, and engineering directs curriculum development towards balanced mixture of courses that will support integration of converging and enabling disciplines to meet the challenges of education, research, and innovation ${ }^{1}$. Many approaches leverage the Kolb model of experiential learning, where knowledge is created via the transformation of an experience as it is connected to theory ${ }^{2}$. Direct experience is needed to establish engagement of the students and showcase the real-world phenomenon $^{3}$. An example of a 'grasping' event is direct immersion ${ }^{4}$ or participating in a virtual environment ${ }^{3}$. After this event, learning can take place through a guided process. The learner will reflect and attempt to connect the experience to current understanding of concepts and then attempt to abstract the concept by creating a model or theory about the phenomenon and finally test the model or theory ${ }^{2}$. This approach challenges students to engage active learning by putting into practice the concepts and ideas explicated in lecture-based courses. Inspired by the Kolb 
approach to guided experiential learning, the instructors aimed to renovate a didactic course into an interactive immersion experience.

\section{Course Background}

BIOE 120: Introduction to Bioengineering serves as an introductory course for incoming freshmen, transfers, and students pursuing the Bioengineering Minor. Previously, the course consisted of a series of guest lectures once a week and majors attended a second meeting each week for additional information. This second meeting was used to discuss options for area of study, course selection, career options, and to have current students speak about their experiences. The instructor also provided information about campus and college resources of which, students may not be aware their first year. Although this information was beneficial, it did not add to curricular content and was a missed opportunity for engagement in Bioengineering. In fall 2014, the college and campus resources information was moved from BIOE 120 to a seminar series now called BIOE 199: Undergraduate Seminar, and a new element was added to enhance bioengineering engagement. This new element was a virtual internship offered by the Epistemic Games group at the University of Wisconsin-Madison. Epistemic Games internships are completely virtual and utilize online simulations to guide students in thinking analytically and utilizing engineering skills to solve big problems, as well as work in virtual teams ${ }^{6}$. Students participated in the internship once a week during class time to work on an assignment with their supervisors and complete a project by the end of the semester. Students worked on Rescutek, where students design a powered exoskeleton, and Nephrotex, where students design a kidney filtration membrane. Students worked in teams of 4-6 on projects for 5 weeks then teams were mixed up and they continued work on the project for 4 more weeks. Feedback on this immersive experience was positive but many students wanted similar opportunities to engage with medicine and research.

\section{Renovated Course Design}

In fall 2015, the instructor expanded this practice further by offering BIOE 120 in 3 professional formation tracks: industry, medical, and research. The industry track consisted of a career focused lecture and Nephrotex game; the medical section featured a local clinician who coordinated guest lectures to give overviews of the different branches of medicine including opportunities for bioengineering innovation within them and 3 hours of volunteer shadowing/observation at local hospitals; and a research section with a lecture in research principles and 3 hour lab shadowing. Each instructor assigned career specific learning outcomes for the class (Table 1). Students were also required to keep a weekly journal to reflect on their immersion experiences.

\section{Table 1. Description of the learning outcomes for each professional formation section of BIOE 120}

\begin{tabular}{|l|l|l|}
\hline \multicolumn{1}{|c|}{ Clinical Section } & Research Section & Industry Section \\
\hline $\begin{array}{l}\text { Provide perspectives of the practice } \\
\text { of medicine }\end{array}$ & $\begin{array}{l}\bullet \text { Identify ethical considerations in } \\
\text { bioengineering research } \\
\text { - Prepare an academic Curriculum } \\
\text { Vitae }(\mathrm{CV})\end{array}$ & $\begin{array}{l}\bullet \text { Describe career opportunities for } \\
\text { bioengineers } \\
\bullet \text { Identify ethical issues in } \\
\text { bioengineering products }\end{array}$ \\
\hline
\end{tabular}




\begin{tabular}{|c|c|c|}
\hline $\begin{array}{l}\text { o Engage in industrial process } \\
\text { (workflow) discovery } \\
\text { o Propose problem solving and } \\
\text { ideation in the clinical context } \\
\text { ○ Identify variables } \\
\text { o Alignment of technology to } \\
\text { assessment and measurement of } \\
\text { variables. } \\
\text { Develop foundational skills as a } \\
\text { lifelong learner }\end{array}$ & $\begin{array}{l}\text { - Identify opportunities for } \\
\text { undergraduate research } \\
\text { - Identify skills and knowledge for } \\
\text { participating in bioengineering } \\
\text { research } \\
\text { - Identify careers in bioengineering } \\
\text { research } \\
\text { - Work in teams to create a poster }\end{array}$ & $\begin{array}{l}\text { - Identify skills and/or knowledge } \\
\text { needed to be competitive in the } \\
\text { bioengineering job market } \\
\text { - Work in teams to identify and } \\
\text { evaluate design considerations } \\
\text { (e.g., economical) } \\
\text { - Describe and interpret data } \\
\text { - Create a poster to describe a } \\
\text { design }\end{array}$ \\
\hline
\end{tabular}

\section{Preliminary Results}

Comments from end of course evaluations and a voluntary survey were reviewed to identify major and minor themes. Responses to multiple choice questions pre and post show that students felt participating in the course increased their confidence in their choice of major, yet many students indicated they wanted to experience all three options (industry, research, and clinical) in one semester. The instructors also performed analysis of open-ended responses asking the benefit of the program. These were categorized into those who explicitly mentioned the immersion as a positive experience and those who did not mention or said negative comments about the experience. While the instructors viewed the immersion experience as the most beneficial aspect of the course, it was surprising to note the lack of appreciation of the immersion experience from the students, with only $20 \%$ of the industry section, $73 \%$ of the research section, and $46 \%$ of the clinical section explicitly indicating the benefit in the course evaluation. The main reason cited for the lower result in the industry section was lack of physical interaction, since that group used a simulation.

\section{Challenges and Future Directions}

Although feedback was largely positive from both instructor and students, challenges arose and improvements are planned for the next offering.

One challenge encountered by the team was enrollment management. Although the overall number is limited to the class size of incoming freshmen, it was difficult to predict section enrollment. Some students were turned away from the research and clinical section due to limited capacity for shadowing assignments for the pilot offering. In addition, many students also expressed a desire for more than one experience in the course. The instructors are exploring options to allow students to perform multiple immersion experiences in one semester (either all of the options or at least two options of research, clinical, and industry). Another potential solution is offering the course year-round to allow flexibility in registration and access to multiple immersion experiences.

To better align the immersion time and type of experience between clinical, research, and industry, the instructors are evaluating the potential to partner with local industry to provide the industry section a face-to-face immersion experience. The team hopes that this will bring the satisfaction with the experience up to the level of the other sections. 


\section{References}

1. Zenios, S.Makower, J,Yock, P, Brinton, T.J., Kumar, U.N.,Denend, L., Krummel, T.m. (2009). Biodesign: The Process of Innovating Medical Technologies. Cambridge: Cambridge University Press.

2. Kolb, David A. (1984) Experiential Learning Experience: Experience as the Source of Learning and Development. Prentice-Hall, Inc., Engelwood Cliffs, N.J.

3. Clark, R. W., Threeton, M. D., \& Ewing, J. C. (2010). The potential of experiential learning models and practices in career and technical education \& career and technical teacher education.

4. Bleakley, A. (2006). Broadening conceptions of learning in medical education: the message from teamworking. Medical education, 40(2), 150-157.

5. De Freitas, S., \& Oliver, M. (2006). How can exploratory learning with games and simulations within the curriculum be most effectively evaluated? Computers \& education, 46(3), 249-264.

6. Shaffer, D. W. (2006). Epistemic frames for epistemic games. Computers \& education, 46(3), 223-234. 